ISSN 1676-3742

\title{
Libanio, o teólogo que pensou sobre/com a juventude
}

\author{
Libanio, the theologian who thought \\ about/with young people
}

Afonso Murad

\section{Resumo}

$\mathrm{O}$ artigo reflete sobre a contribuição do teólogo brasileiro João Batista Libanio para compreender a complexa realidade juvenil e atuar pastoralmente nela. Inicia-se com breves relatos e depoimentos a respeito da relação efetiva de Libanio com os jovens. A seguir, apresenta três características básicas da articulação do pensamento deste grande teólogo: perspectiva dialética, método genético-estrutural e percepção holística. Com este quadro teórico, desenvolvem-se as principais tendências pessoais na juventude atual, com as respectivas sugestões pastorais, tal como aparece na obra "Para onde vai a juventude?". Por fim, delineia-se suscintamente o quadro das demais tendências, nos âmbitos da vida escolar, das relações comunitárias, do mundo cultura, do espaço religioso, na sociedade e na política. Visa-se assim oferecer ao leitor/a algumas chaves de leitura elaboradas por Libanio, para ajudá-lo/a a lidar pastoralmente com a juventude e estimular o seu protagonismo.

Palavras-chave: João Batista Libanio, Juventude pós-moderna, Evangelização da juventude.

\section{Abstract}

The article reflects on the contribution of brazilian theologian João Batista Libanio, to understand the complex reality of young people and act pastorally with it. It begins with brief reports and testimonials about the existential relationship 
Libanio with young people. The following are three basic characteristics of the articulation of the thought of this great theologian: dialectical perspective, genetic-structural method and holistic perception. With this theoretical framework, it develops the personal major trends in today's youth, with the pastoral suggestions, as it appears in the book "Where is the youth". Finally, is outlined succinctly the situation of the other trends in the areas of school life, community relations, world culture, religious space, society and politics. The aim is thus to offer the reader some Keys, prepared by Libanio, to help him deal pastorally with young people and encourage their active involvement.

Keywords: João Batista Libanio, Postmodern Youth, Evangelization of youth.

\section{Introdução}

$\mathrm{Na}$ juventude aparecem, de forma particular e original, os direcionamentos e as perspectivas do presente e do futuro da sociedade. A ação pastoral, tarefa perene e sempre nova da Igreja, se volta para esta realidade plural, diversa, cambiante, desafiadora. Busca compreender o que está acontecendo com os/as jovens e ensaia processos de evangelização, com linguagem e estilo apropriados. Vê-se nos/as jovens não somente destinatários, mas sim interlocutores e protagonistas. Busca-se compreender sua realidade com olhares múltiplos, que contemplem a subjetividade, as relações interpessoais, a cultura, as estruturas sociais e a religiosidade. Aqui reside, na verdade, a grande distinção entre uma pastoral conservadora e a inovadora.

João Batista Libanio, conhecido teólogo brasileiro, deixou uma contribuição inegável, para compreender o mundo dos/as jovens e atuar pastoralmente com eles. Neste artigo apresentaremos uma pequena parte de seu trabalho, para munir o leitor/a de chaves pastorais que, esperamos, sejam úteis para a educação e a evangelização da juventude.

\section{Libanio, teólogo com os/as jovens}

\section{O ciclo prática-teoria-prática}

A primeira questão que desperta a curiosidade do leitor/a seria: a reflexão de Libanio é meramente intelectual, ou se baseia também em experiência de vida e contato efetivo com os/as jovens? 
Depois que terminou seu doutorado em Roma, Libanio voltou ao Brasil para trabalhar como professor de teologia. Mas, desde o início, não se limitou ao ambiente acadêmico. No início da década de setenta se desenvolveram no Brasil alguns movimentos juvenis, inspirados no espírito de renovação do Concílio Vaticano II. Alguns deles, sob a influência dos Cursilhos de Cristandade, que utilizavam uma metodologia existencial, baseado em forte impacto emocional, testemunhos pessoais contundentes e apelo à mudança de vida. Os mais conhecidos foram o TLC (Treinamento de lideranças cristãs) e o CJC (Cursos da Juventude Cristã) ${ }^{1}$. Inicialmente, Libanio colabora com o CJC. Empenha-se apaixonadamente na formação de jovens no Movimento. No entanto, logo percebe que é necessário ir além daquela proposta pastoral.

Com alguns jovens, Libanio inicia em 1972 um grupo alternativo, taxado pelos adversários como "tropa maldita". A tropa reunia jovens com grande potencial humano, intelectual e espiritual. Buscavam (e encontraram) novo espeço de reflexão e atuação crítica. O Brasil estava sob o domínio do regime militar, que com sua ideologia de "segurança nacional", perseguia as lideranças e difundia sua ideologia alienadora. Libanio ensinou e aprendeu muito com a tropa. Estabeleceu laços profundos com os jovens. Acompanhou-os durante seu processo de amadurecimento. Dentre seus discípulos, destacam-se as conhecidas figuras de Chico Pinheiro (repórter) e Faustino Teixeira (professor e referência nacional em Ciências da Religião). O testemunho do professor Faustino fala por si.

Eram jovens de Belo Horizonte, Sete Lagoas, Juiz de Fora, Volta Redonda, Rio de Janeiro e depois São Paulo. Em tempos difíceis da conjuntura política nacional, o grupo se reunia regularmente com Libanio, cerca de quatro vezes por anos, sobretudo na cidade de Juiz de Fora para tratar uma diversidade de temas envolvendo política, filosofia, cultura e religião. Muitas lideranças em vários âmbitos profissionais nasceram desse grupo, que se manteve unido por mais de três décadas, e que ainda se encontra em momentos singulares. Foi um espaço particular de presença e atuação de Libanio, onde pôde imprimir sua marca de formador, mestre espiritual e iniciador intellectual ${ }^{2}$.

\footnotetext{
${ }^{1}$ No correr de sua trajetória, o CJC passou por várias mudanças e se diversificou. Atualmente, há muitos CJCs no Brasil. Um de seus ramos se chama "Comunidade de Jovens Cristãos". Ver, por exemplo: http://cjcbasilica.blogspot.com.br/ (acesso em 17/10/14).

2 TEIXEIRA, F., "Cultivo da formação e vida intelectual” in: MURAD, A; BOMBONATTO, V. (orgs), Teologia para viver com sentido. Homenagem aos 80 anos do teólogo João Batista Libanio. São Paulo: Paulinas, 2012, p. 165-166.
} 
A experiência de Libanio com a tropa tornou-se fonte de inspiração para o seu primeiro livro sobre a juventude ${ }^{3}$. Também concorreram com elementos teórico-práticos os minicursos e encontros de lideranças jovens, que reuniam até centenas de pessoas, em São Paulo, no Rio de Janeiro, em Belo Horizonte e em Itaici. Especial importância ganharam os Cursos de "Formação da consciência crítica", relacionados com obras publicadas com este título ${ }^{4}$. Destinavam-se a potenciais agentes de pastoral, jovens e adultos, religiosos/as consagrados e presbíteros.

Libanio sempre teve em mente a necessidade de formar novas lideranças. Identificava pessoas com potencial, oferecia-lhes oportunidades de desenvolver suas aptidões, ensinava-lhes a pensar, a refletir, a escrever e a produzir. Associava jovens teólogos à sua produção literária, de forma a lança-los neste campo de conhecimento. Assim sucedeu por exemplo, com Maria Clara Bingemer, convidada a escrever com ele a obra de Escatologia, da coleção "Teologia e Libertação"s.

De Libanio emanava um dinamismo interno que cativava os jovens. Brilhante na arte de ensinar, mesclava nas suas conferências o rigor dos conceitos com a beleza das analogias, a leveza de anedotas, os fatos contados de forma hilária, que faziam rir e pensar.

Libanio conjuga em sua vida diferenças facetas que constituem o segredo de sua rica personalidade: é o mestre, o professor, o conferencista, o escritor e o pastor. E essa conciliação é feita com amor e naturalidade, como ele mesmo explica: "o professor comunica seu saber teológico. O conferencista amplia seu raio de comunicação. $\mathrm{O}$ escritor formula para si e para os outros nas letras pensadas seu saber. Na pesquisa penetra o mundo desse saber. Na pastoral confronta esses conhecimentos com a realidade ${ }^{6}$.

\footnotetext{
${ }^{3}$ LIBANIO, J.B. O mundo dos jovens. Reflexões teológico-pastorais sobre os movimentos de juventude da Igreja. São Paulo: Loyola, 1978.

${ }^{4}$ LIBANIO, J.B. Formação da consciência crítica. Petrópolis: Vozes. Vol 1: Subsídios filosóficoculturais. 1978; vol 2: Subsídios sócio-analíticos, 1979; vol 3: Subsídios psicopedagógicos, 1979. ${ }^{5}$ LIBANIO, J.B; BINGEMER, M.C.L. Escatologia cristã. Petrópolis: Vozes, 1985. Também o autor deste artigo recebeu, desde os inícios de sua missão, orientação do Padre Libanio. A convite de seu mestre, produziu-se uma obra teológica a quatro mãos. Cf. LIBANIO, J.B; MURAD, A. Introdução à Teologia. Perfil, enfoques, tarefas. São Paulo: Loyola, 1996. (8 Edição revista e ampliada em 2012).

${ }^{6}$ TEIXEIRA, F. in: KONINGS, J. (org). Teologia e pastoral. Homenagem ao Pe. Libanio. São Paulo: Loyola, 2012, p. 188. (Homenagem aos 70 anos do Padre Libanio).
} 
Chamado em muitos lugares para conferir palestras e orientar retiros, Libanio conservava a simplicidade e a proximidade. Em muitos momentos, dispensava a formalidade do evento para se fazer próximo de quem o escutava.

Escutar Padre Libanio era escutar um homem de Deus falando de Deus. De Deus Amor que se faz presença na humanidade. Ouvia-se um homem que falava da realidade social e religiosa com propriedade. Um homem idoso, com espírito jovem, dialogando com a juventude. Pessoa de profunda espiritualidade vivendo "a contemplação na ação", como orientava Santo Inácio de Loyola, fundador da Companhia de Jesus. Enfim, era escutar um homem, sacerdote, pastor e professor iluminado com palavras e ações?

Atento às rápidas e surpreendentes mudanças culturais que tocam especialmente os jovens, Libanio publica em 2004 uma obra sobre a realidade juvenil, bem articulada e fundamentada, já no horizonte da influência da pós-modernidade ${ }^{8}$. Anos mais tarde, escreve o terceiro e último livro a respeito da juventude, em perspectiva pastoral ${ }^{9}$. Nesta obra Libanio demonstra amplo conhecimento das principais tendências que marcam a(s) juventude(s). Com análise acurada descortina tais tendências nos seguintes âmbitos: pessoal, na vida acadêmica, nas relações comunitárias, no mundo cultural, no mundo religioso, na sociedade política. Trata-se de roteiro indispensável para educadores e agentes pastorais que atuam junto aos jovens.

\section{Como Libanio articula seu pensamento}

Em entrevista para o "Jornal de Opinião", posteriormente publicada como anexo na obra em homenagem aos 80 anos do nosso teólogo ${ }^{10}$, Libanio apresenta o eixo metodológico de sua produção teológica, caracterizando-a como dialética, genético-estrutural e heurística.

\footnotetext{
${ }^{7}$ Depoimento de Edemilton dos Santos, Professor, agente de Pastoral e membro da Rede Celebra, por ocasião da morte do Padre Libanio.

${ }^{8}$ LIBANIO, J.B. Jovens em tempos de pós-modernidade. São Paulo: Loyola, 2004.

${ }^{9}$ LIBANIO, J.B. Para onde vai a juventude? Reflexões pastorais. São Paulo: Paulus, 2011.

${ }^{10}$ Entrevista a Flávio Senra in: MURAD, A; BOMBONATTO, V. (orgs) Teologia para viver com sentido. São Paulo: Paulinas, 2012, p. 208-209.
} 


\section{(A) Perspectiva dialética}

Consiste o esforço de analisar e pensar a realidade em diversos momentos. Libanio parte do axioma básico: "toda realidade humana padece de ambiguidade, carregando dentro de si positividades e negatividades, mas não na mesma medida". Ao esquadrinhá-la, em primeiro lugar percebe-lhe o lado positivo. Então se pergunta como reafirmar no contexto atual tal positividade, reforçando-a. No segundo momento, volta-se para a negatividade, o limite, o caráter paralisante da realidade. Assume então a posição inversa: como negar no momento presente tal negatividade? Assim avança positivamente. E, no terceiro momento, interroga sobre novas possibilidades para caminhar, triplicemente: afirmando, negando e criando. Para Libanio, tal metodologia tem várias vantagens. Parece-lhe honesta. Evita radicalismos. Desarma sutilmente os adversários.

Libanio sabe entrecruzar buscas e abrir novas possibilidades. Procura entender o real e suas múltiplas faces. Os modos de pensar são oscilantes e se remetem um ao outro. Como em uma nave, o conhecimento humano é sempre um convite para içar as velas e recolher novas questões para novos começos. Sabe pôr-se em viagem para enfrentar as vias incertas e difíceis do conhecimento teológico ${ }^{11}$.

\section{(B) Método genético-estrutural}

Tal método, diacrônico-sincrônico, adotado por Libanio, joga com dois tipos de análise. Lança um olhar histórico para o percurso de gestação de tal realidade até o momento atual (genético ou diacrônico). A seguir, detém-se no concreto para captar-lhe a estrutura básica, diferente de elementos agregados secundários (estrutural ou sincrônico). Assim a realidade aparece com maior clareza e transparência no devir até agora e na consistência presente.

Libanio mantém diálogos críticos com teólogos clássicos nacionais e internacionais. Ensina-nos que, ao fazer pesquisa, não se trata de testar ou atestar, mas antes de indagar, perguntar e levantar questões de maneira nova. É um pensador ativo e metódico. Um intelectual em busca de significado / significados ${ }^{12}$.

\footnotetext{
${ }^{11}$ PASSOS, M. "Um teólogo em movimento: caminhos e diálogos" in: MURAD, A; BOMBONATTO, V. (orgs), op.cit, p. 175

${ }^{12}$ Idem, p. 173-174.
} 


\section{(C) Percepção heurística}

Característica típica do pensamento de Libanio. Ao ler algum autor ou texto, ele não se contenta em reproduzi-lo ou citá-lo eruditamente. Vai muito além. Põe-se a pensar, a refletir e a escrever algo diferente, mas cuja inspiração, sugestão ou provocação vieram do texto lido. No final, já não se trata do texto ou do autor em questão, mas de reflexão pessoal, desencadeada, porém, por eles. Como afirma o próprio Libanio: "não nos dedicamos a pesquisar até os meandros do texto, muito a gosto da atual academia e sim de pensar, de arquitetar outros arcabouços teóricos".

A produção teológica de Libânio é um convite para se pensar o diverso, a multiplicidade, a não submissão. Convite para criar cenários de emancipação e cruzar o arco em busca de novos horizontes - avançando, dialogando, questionando, abrindo outras veredas ${ }^{13}$.

Mais do que um método próprio, Libanio desenvolve uma forma holística e sapiencial de ver o mundo, de penetrar nos seus meandros com um olhar de fé, que busca compreender, acolher e transformar. Inteligência brilhante, aguda e cordial.

A idade e a meditação da vida o fez mais que teólogo. A teologia e a filosofia constituem sua matriz. Mas transcendeu. Fez-se um sábio. Captou outras dimensões do real dentro do qual Deus também se esconde e quer ser ai descoberto. Sábio é aquele que cata estas pepitas divinas nos prados dos vários saberes. Libanio sabe fazer esta garimpagem: desde o estudo da consciência critica, passando pelas ponderações sobre o futuro da religião, penetrando do universo complexo da cidade, na busca metódica do conhecimento até desembocar na espiritualidade na qual se move como quem saboreia o que pensa e diz ${ }^{14}$.

\section{Para onde vai a juventude? Tendências e pistas pastorais}

Apresentaremos, a seguir, uma síntese do pensamento de Libanio a respeito da juventude atual, com as respectivas pistas pastorais, como está formulado na sua obra "Para onde vai a juventude?", já citada.

Toda análise supõe um ponto de vista. Se os jovens descrevessem as próprias tendências, diriam coisas diferentes do olhar adulto. Por isso, Libanio

\footnotetext{
${ }^{13}$ Idem, p. 180.

${ }^{14}$ BOFF, L. "João Batista Libanio: amigo e irmão. Um testemunho pessoal” in: MURAD, A; BOMBONATTO, V. (orgs), op.cit, p.196.
} 
recomenda "discutir com eles essas mesmas tendências e ouvir o que eles dizem a respeito delas. A circularidade dos olhares enriquece. Interessa captar os pontos da análise feita com os quais eles se identificam, dos quais divergem ou os quais analisam valorativamente de modo diferente" (p. 6) ${ }^{15}$.

A juventude fascina pelo paradoxo da vulnerabilidade e da potencialidade. Deixa para trás a serenidade e segurança da infância, mas ainda não atingiu a solidez da idade adulta. Porque ainda não aterrissou na maturidade, dispõe do infinito do céu para voar. Considerar simultaneamente a precariedade e o vigor juvenil faz com que análise não caia nos extremos do discurso negativista nem da exaltação da juventude (p.7). Busca-se perceber aspectos fundamentais da juventude de hoje numa perspectiva processual, com interesse pastoral e na dupla valência de virtualidades e limites (p.9).

Por que Libanio escolhe "tendência" como categoria central? "Ela permite captar melhor o movimento em que se encontram os jovens. Eles vêm de uma cultura anterior tradicional e moderna e mergulham na pós-modernidade. Há enorme variedade de velocidade nesse processo" (p.9). A categoria tendência deixa em aberto em que ponto os jovens estão, pois simplesmente aponta para o movimento. Em cada tendência, um jovem concreto encontra-se próximo do ponto de partida, no meio caminho ou na ponta. Com isso, indica-se o movimento, mas não onde a pessoa se situa. Assim, ajuda entender a realidade atual, movediça, e permite constatar em que altura da tendência está o jovem ou grupo de jovens (p.10).

Consoante a perspectiva heurística e dialogal, Libanio propõe que os três itens de cada tendência - descrição, análise crítica e sugestões pastorais - devam ser discutidos, para que a realidade juvenil se torne transparente e estimule o desenvolvimento da capacidade crítica do próprio jovem. "As melhores conclusões surgirão de dentro das discussões. O livro oferece subsídios para desencadear o processo e não fechá-lo. Portanto, estamos diante de um livro aberto, incompleto, com a simples pretensão heurística de provocar a imaginação dos envolvidos na pastoral dos jovens juntamente com eles" (p.11)

Selecionaremos aqui algumas tendências pessoais apresentadas por Libanio. Reuniremos no mesmo ítem tendências similares.

\footnotetext{
${ }^{15}$ Visando tornar o texto mais fluente, adotamos o procedimento didático de simplesmente apontar o número da página no corpo do texto (e não em nota de rodapé), referente ao pensamento de Libanio na obra: "Para onde vai a Juventude", São Paulo: Paulus, 2011. As citações literais estão entre aspas.
} 


\section{Algumas tendências pessoais na juventude}

(1) DE juventude de desenvolvimento fisico lento, mas que assume responsabilidades cedo PARA juventude de desenvolvimento físico acelerado e de menor maturidade psicoafetiva.

O tipo de alimentação, o cuidado com o corpo desde cedo, a frequência de esportes e academias e o incentivo ao desvelo pela saúde têm favorecido o amadurecimento físico precoce dos jovens (p.13). No entanto, ao lado da maior maturação biológica, nota-se uma significativa lentidão do amadurecimento psicológico, a ponto de configurar grande defasagem. A precocidade do crescimento físico conflita com a fragilidade psíquica. Sob a aparência de um corpo de adulto, esconde-se a debilidade de criança (p.15). Ora, a maturidade afetivo-emocional depende da síntese existencial que a pessoa constrói. Quanto mais plural e diversificada se torna a vida dos jovens, com a entrada enorme de fatores sociais, culturais, afetivos, tanto mais lenta se elabora a própria maturação, embora mais rica e polimorfa" (p.14).

$\mathrm{Na}$ sociedade rural ou suburbana, os jovens tinham que assumir logo muitas responsabilidades. Amadureciam em vários aspectos, embora privados de amplo horizonte cultura. Hoje, livres do trabalho infantil, com a prolongamento da formação acadêmica, ganha-se em riqueza humana. No entanto, os jovens pagam o preço de amadurecimento lento. Não assumem decisões que implicam certo caráter permanente ou duradouro, como a relação a dois e a profissão (p.15).

Como sugestão pastoral para lidar com esta tendência, Libanio indica uma "pedagogia que sinalize com clareza o campo de responsabilidade em cada fase etária" (p.16). Deve-se descobrir em que campo e em que condições a juventude de hoje se depara com exigências inadiáveis. É verdade que sem limites e sem cobranças, dificilmente alguém amadurece. Mas essas não podem vir de forma autoritária. A questão pedagógica consiste em perceber até onde o jovem suporta o impacto da realidade. A dureza excessiva o conduz à fuga; a vida fácil sem cobrança o deixa irresponsável. Então, “o amadurecimento se processa com exigências dosadas, sucessivas e continuadas, que o põem em ritmo de responsabilidade. Ele precisa responder a elas, do contrário a vida se lhe torna impossível” (p.17). 
(2) DE juventude que prezava o dinamismo projetivo PARA juventude que valoriza o dinamismo explorativo. Tal tendência se articula com outra, assim formulada: DA preocupação com a felicidade sólida e permanente PARA o contentar-se com momentos felizes, sem continuidade e sem preocupação com o futuro.

$\mathrm{Na}$ década de 60, parte da juventude investia em sonhos futuros, em vista de construir uma nova sociedade. Já os grupos adaptados ao sistema eram animados pelo futuro profissional e pelo desejo de ascensão social. "O presente se pensava em vista da construção profissional, familiar, econômica. Sacrificavam-se comodidades momentâneas em prol do futuro, do projeto de vida (..) Faziam-se escolhas a se realizarem a longo prazo" (p.17). Ora, a pós-modernidade desloca o acento para o presente. Os jovens querem "experimentar o momento". Com isso, correm o risco de se deter em experiências sem tomar decisões, sem compromisso com a vida a vir. Eles têm dificuldade de gerir as emoções e de sustentar atitudes permanentes.

É comum encontrar jovens adultos que permanecem na casa dos pais, com liberdade em vários aspectos, aproveitando as facilidades de ter onde morar, cama e roupa lavada (p.18). Tal fato indica, entre outras coisas, a junção de relativa autonomia e comodidade.

A cultura pós-moderna acentua a centração do sujeito em si mesmo, com traço narcisista. Conjugada com a primeira tendência (maturidade lenta), rejeita-se a responsabilidade que a vida adulta impõe. "Por faltar a força do idealismo e da utopia e por concentrar-se no presente, eles facilmente lançam mão de mecanismos de fuga para enfrentar as durezas da realidade" (p. 19). Por exemplo, alguns prolongam o tempo de sono ou se entregam a ele toda vez que emerge um problema.

É positivo valorizar o presente e vivê-lo com intensidade (p.35). O problema reside na inversão de relação entre presente e futuro. Se para jovens de décadas anteriores o idealismo sacrificava o presente por ideais muitas vezes inalcançáveis, "a geração nova desconhece tais sonhos utópicos, ao testar a realidade, aos poucos, no cotidiano" (p. 20). Utilizando uma metáfora da mitologia grega, dir-se-ia que Prometeu cedeu lugar para Narciso: da busca incessante de conquistas para um satisfazer-se consigo mesmo.

Libanio mostra como presentismo e narcisismo constituem um forte amálgama, relacionado à negação do compromisso de vida adulta e da própria ética: "substitui-se a felicidade como estado permanente, vislumbrado no 
futuro e do qual a vida presente participa parcialmente em vista dele, pelo anseio por momentos intensos de felicidade sem preocupação com o futuro" (p.28). Ora, psicologicamente isso significa o prolongamento da adolescência, sem aceitar ancorar na vida adulta (p.30). Na sequência desse deslocamento para o presentismo do prazer perde-se a consciência de história. Tudo se percebe como "agora". Ora, com o desaparecimento da história, a ética se dissolve" (p.34).

Que sugestões pastorais são viáveis, neste quadro tão impactante? Libanio resgata algo fundamental. "O ser humano, por mais acomodado que esteja, possui orientação para a Transcendência. A ela se prendem os idealismos. E na idade jovem tal dinamismo se acentua" (p.22). Então, deve-se de propor algo que mova o espírito de sonho, de superação de si, de ultrapassagem da rotina. Nessa linha, colocam-se os retiros espirituais e as metodologias que favoreçam a elaboração do projeto de vida, e o acompanhamento que se segue. A superação do mero presentismo se faz com longo processo que inclui recordar e narrar o passado, acolher as chances do presente com realismo e vislumbrar o futuro (p.23). Na elaboração do projeto de vida, evite-se os extremos do detalhismo, que tolhe a criatividade, ou deixar pontos soltos e sem concretude.

Pastoralmente, deve-se ajudar os jovens a diferenciar os "momentos de felicidade" da "felicidade", resultante de longo e contínuo processo. Trata-se de uma pedagogia do desejo, que "consiste em oferecer aos jovens ocasiões em que eles consigam vivenciar desejos profundos e refletir sobre o vazio de outros desejos" (p.37). Na perspectiva transcendente teologal, tal pedagogia se volta para a questão básica do sentido, de Deus. O primeiro passo consiste em encontrar pequenos sentidos nas ações concretas do cotidiano. A seguir, perceber como essas se enquadram num horizonte maior. O jovem narra sua vida cotidiana. Em seguida, volta-se para a Bíblia em busca de luz sobre tais ações, do Sentido maior. Assim aprende a discernir a Deus presente no cotidiano. À luz da fé cristã, identifica a "presença deste Sentido radical nos pequenos sentidos da vida como instância última de juízo, de crítica, de motivação" (p.39).

Além disso, a pastoral atua para desmitologizar os heróis midiáticos, que povoam a fantasia dos jovens e os seduzem com suas medíocres imagens de felicidade. Na mesma linha, torna conhecido o perfil de cristãos felizes e engajados em causas sociais e religiosas, como Dom Romero, Irmã Dorothy e Chico Mendes. Neles os jovens encontram referências de valores, de realização humana e compromisso transformador. 
Libanio aponta diversas tendências da juventude no âmbito da sexualidade e afetividade. Para efeito didático, reuniremos algumas delas, concentrando-nos sobretudo nas pistas pastorais.

(3) DE relação afetiva lentamente preparada PARA o amor com certa reserva em face do sexo, para encontros afetivo-sexuais intensos e descomprometidos, sem perspectiva de continuidade e de amor (p.40). DA dificuldade das confidencias pessoais PARA aberturas afetivas e sexuais via Internet (p.57). E ainda: DA moderação na vivência do prazer PARA sua crescente intensificação (..) pela exacerbação do prazer sexual como algo normal, fácil e sem medos nem fantasmas (p.62).

É notório que aconteceu uma rápida mudança referente à diferença de valoração psicossocial dos comportamentos afetivo-sexuais. Desaparecem as etapas clássicas de encantamento, namoro, noivado e matrimônio. Suprimem-se as regras tradicionais. Mais ainda. Inverte-se a experiência. Acelera-se a experiência sexual sem cultivar o afeto. Os jovens temem as relações afetivas comprometedoras e arriscam facilmente as intimidades sexuais sem medir as consequências. Não se reflete sobre o significado do ato. Vale a fruição presente (p.41). Em breves palavras: adultos no sexo e infantis nos comportamentos, conforme se apresentou na primeira tendência. Vida sexual ativa de forma precoce. Mas não se assumem responsabilidades nem vínculos definitivos. Sexo sem vínculos e sem responsabilidade. "O que antes se julgava como aventura irresponsável e desviada, hoje se tornou normal e aceito” (p.41).

Os jovens lidam com o sexo de modo realista e pragmático, tanto para o bem, quanto para o mal. Esmaece-se o caráter ético das relações sexuais. Vulgarizado, o sexo também perde a dimensão simbólica. Não se tem consciência da gravidade da crise do vínculo (p.43). Ora, é necessário romper vários vínculos, no processo de autonomia e maturidade. No entanto, torna-se humanizador criar e manter outros vínculos, não mais por imposição, mas sim pela compreensão social de seu sentido (p.44).

As gerações anteriores guardavam certa reserva em relação à vida íntima. A cultura pós-moderna, centrada na criação de imagem e na publicização, rejeitam tal postura. Com a internet, acontece real exposição afetiva nas relações virtuais. As revelações da intimidade não encontram limite. Confunde-se o foro pessoal com o público. Os jovens se expõem com facilidade, para quem querem, assumindo identidade própria ou fictícia (p.57-59). 
O processo de maturação do jovem passa pela superação dos extremos do tabu e da banalização. Como a pastoral responde a este desafio? Em primeiro lugar, promovendo espaços de partilha, discussão e esclarecimento em torno das experiências afetivo-sexuais, em grupos juvenis. Mas não somente isso. Deve-se passar do nível de mero relato para a descoberta do nível simbólico. Isso significa perguntar-se pelo sentido dos gestos, pelo mistério que eles comportam. "Ao desvelar e narrar a interioridade, o jovem se expõe a ser ajudado. Nesse momento, interfere o pedagogo com a dupla função de fazer o jovem ver a verdade de si e submetê-la ao crivo da crítica" (p.45).

A confusão de cabeça e de comportamento, no que diz respeito à sexualidade, desnorteia os jovens. Visando ter um norte, promove-se a crítica às atitudes e comportamentos afetivo-sexuais. Mas essa prática implica a construção conjunta de um quadro referencial de valores, o que exige muito tempo e energia. "Só por meio de lúcidas discussões, conversas, motivações, explanações conseguirão maior clareza a fim de recompor-se nesse campo" (p. 45). Os processos educativos em relação à sexualidade, na família, da escola e na Igreja, serão eficazes para os jovens na medida em que se efetive a proximidade de adultos sensatos, acolhedores e competentes.

Um tema imprescindível nessa discussão é o uso consciente da internet. O ciberespaço midiático tem servido como ocasião de iniciação sexual e de perversão de muitos jovens e adultos. Neste campo, adverte Libanio: "Sem claro e corajoso diálogo dos pais e educadores com os jovens a respeito desses meios informativos a batalha da formação para a sexualidade está perdida. Nesse campo se joga o futuro dessa nova geração" (p.52). Mais. Cabe à pastoral utilizar o espaço midiático, aproveitar das possibilidades de cultura virtual para orientar os jovens. Ajudá-los a diferenciar o real da simulação. Articulam-se assim os insubstituíveis encontros face a face, presenciais, com os virtuais. Promovem-se "redes do bem".

Em relação à tiranização do prazer, o caminho pastoral não vai na linha da repressão, mas sim na ampliação e sublimação do prazer. Como? Sem negar a relevância do prazer sexual, trabalha-se no desenvolvimento de três espaços prazerosos: o lúdico, o estético e o religioso. Eles completam e ampliam o horizonte de satisfação (p.70). Trata-se de uma pedagogia do prazer. O lúdico nos introduz no espaço da gratuidade, da fruição, onde se manifesta alegremente o coração de criança. A experiência estética coloca jovens e adultos diante do belo que extasia. A mística religiosa reconecta o ser humano com a Fonte da Vida e com a comunidade que celebra a presença de Deus. Simultaneamente, aquieta o coração e confere-lhe paz inquieta. 
Convém recordar as experiências missionárias com jovens, que convivem durante um período com a população carente, no interior ou na periferia. A descoberta do outro, do rosto do empobrecido, a valorização de sua cultura, a experiência de real interlocução gera um sentimento de satisfação e de busca. O narciso quebra seu espelho. Coloca uma janela em seu lugar, que lhe possibilita abrir-se aos outros e ao mundo.

(4) DE juventude que ouvia muito e falava pouco PARA juventude que quer ser ouvida e falar para a Igreja, para a família, para a sociedade.

A sociedade industrial confinou as crianças e os jovens à família e à escola. Lentamente, os jovens começam a se constituir como um grupo com características próprias. Buscam espaços de autonomia. Passam então da posição de quem escuta muito e fala pouco para uma "pulsão da palavra" (p.73). Tal constatação parece estar em contradição com o fato de que a juventude não domina a língua culta, tem um vocabulário restrito e pobre, usa poucas palavras e muitas gírias, escreve de forma abreviada. Mesmo com estes limites, eles lutam pela liberdade de linguagem, que inclui também gestos, atitudes e comportamentos. Não aceitam censura ao próprio dizer O retardo para alcançar a maturidade, caracterizado na primeira tendência, coexiste com a busca vigorosa e precoce de certa autonomia. "Não têm madureza para falar, mas falam. A cultura presente incentiva-os à iniciativa, à tomada de posição. Eles prezam espaços livres, acolhedores, abertos à troca de ideias, às expressões afetivas, aos questionamentos, às dúvidas e às incertezas" (p. 74).

Ora, a trajetória em vista da livre expressão possibilita adquirir maior autoconsciência. E os jovens a reivindicam, opondo-se à arrogância dos adultos, que negam seu protagonismo. Como considerar as novas formas de linguagem dos jovens, nas quais predomina a oralidade e a gestualidade? "O valor mostra-se na sua pluralidade, rapidez, plasticidade, força impactante. $\mathrm{O}$ limite lhes vem da carência de lógica, da ambiguidade, da pobreza de expressividade linguística" (p.75).

A exaltação unilateral da juventude traz efeitos nefastos. Provoca incapacidade de ouvir os mais velhos, de aprender com sua sabedoria. Assumir protagonismo exige preparação. De outro lado, grande contingente de adultos se omite de sua função, deixando os jovens sem referências fundamentais. Quebra-se assim a cadeia de transmissão e de reelaboração de valores, aquilo que J.L.Segundo, a partir de G. Bateson, denomina a "dêutero-aprendizagem". 
A pastoral, conectada com esta realidade juvenil, estimula o diálogo intergeracional, cria momentos de mútua escuta. "Ora os jovens falam e os adultos escutam, sem interrompê-los. Ora se inverte a jogada, e os jovens se põem a ouvir. Desse duplo jogo de fala e escuta, surgem ideias novas, projetos possíveis. No verdadeiro diálogo, ninguém entra e sai exatamente com as mesmas ideias e conviç̧ões. Ele existe precisamente para gerar um terceiro novo de ambas as partes. Só assim se cresce” (p. 76).

A seguir, empenha-se na busca de consensos em valores fundamentais. Inicialmente, se nomeiam os valores em questão. A seguir, avança-se para interpretá-los e conferir-lhes significado. Explicitam-se os conteúdos de maneira concreta, com sinônimos, exemplos e definições. Para alcançar os consensos, exige-se tempo e espaço de partilha. Hora e lugar de encontro, que se realiza em ambiente agradável e aconchegante, de forma a favorecer a mútua comunicação entre adultos e jovens.

\section{Esquema das demais tendências na obra "Para onde vai a juventude?"}

Para que o leitor tenha uma visão panorâmica do complexo quadro da realidade juvenil traçado por Libanio, apresentaremos a seguir o conjunto das tendências, conforme distintos âmbitos da existência. Certas tendências foram colocadas em proximidade com as semelhantes. Algumas delas, embora já tenham aparecido nas "tendências pessoais", voltam novamente sob outros ângulos, permitindo análise mais apurada e sugestões pastorais apropriadas.

Tendências na vida escolar e acadêmica (p.79-96)

(1) DE pedagogia afeita ao aprender o ensinado e de hábito de leitura PARA pedagogia crítica e menos interessada pelo saber teórico e pela leitura.

(2) DE cultura em que se aprendia a escrita e fala estabelecida PARA a nova escrita da Internet e novo modo de falar.

(3) DE escola com disciplina PARA escola em que os jovens decidem o ritmo.

Tendências nas relações comunitárias (p.97-141)

\section{Família}

(1) DE família estruturada em que os filhos se encontravam frequentemente com os pais PARA aquela marcada por ausência, dissolução dos laços familiares e formação de novas constelações. 
(2) DE família em que os papeis de pais e filhos estavam bem definidos PARA confusão entre eles.

(3) DA necessidade de deixar quanto antes a casa dos genitores PARA vida autônoma sem vínculos, embora prolongando a permanência na casa dos pais.

(4) DO desejo de constituir família PARA o de ter um/a companheiro/a enquanto ele/a satisfizer ao outro/a.

(5a) DA concepção romântica do matrimônio PARA compreensão realista e pragmática.

(5b) DO desejo de ter filhos PARA o de evitá-los a fim de não ligar-se com algo futuro que cerceie a liberdade de aproveitar da vida.

\section{Trabalho}

(6) DA passagem tranquila e normal de sociedade, escola/casa que assegurava a disciplina e oferecia inserção no mundo do trabalho PARA sociedade anômala, sem lugar para os jovens, a gerar incerteza do futuro e trabalho cada vez mais problemático.

\section{Colegas}

(7) DE convivialidade ampla PARA a busca de grupos/tribos afins.

(8) DA predominância dos encontros reais PARA o crescimento das relações virtuais por meio da Internet, a transformarem a mente e o coração dos jovens.

(9) DE juventude a viver única idade cultural PARA a que co-existe com companheiros de várias idades culturais, sob o impacto de globalização massificante.

Tendências no mundo cultural (p.143-181)

(1) DA consciência ética, histórica e utópica PARA a simples consciência do presente.

(2) DA dependência em relação aos mais idosos e às instituições tradicionais PARA crescente e precoce autonomia.

(3) DE cultura marcada pela dualidade e dualismo PARA a predominância da conciliação, tolerância até certo monismo oriental.

(4) DE cultura de certezas PARA relativização generalizada. 
(5) DE valorização da verdade e da ética PARA a substituição pela beleza e a estética.

(6a) DO mundo da natureza PARA o envolvimento com a tecnologia.

(6b) DA concepção de tempo e de lazer ligada à natureza PARA crescente lazer eletrônico ou de esportes competitivos.

(6c) DOS silêncios e sons da natureza PARA crescente e permanente presença do som: música, barulho, ruído.

(7) DE consciência juvenil compacta PARA a fragmentada, fraca e incoerente.

(8) DE juventude estável com aventuras esporádicas PARA juventude envolvida na violência da droga e do crime com vida breve.

Tendências no mundo religioso (p.183-218)

(1a) DA religião institucional PARA práticas religiosas selecionadas conforme a necessidade do momento.

(1b) DE jovem tradicionalmente religioso PARA jovem secularizado e que volta a fazer-religioso de outra maneira.

(2) DE concepção de Transcendência externa PARA imanentização ou para Transcendência na imanência.

(3) DE juventude marcada pela culpa PARA relativização ética.

(4) DE Pastoral da Juventude PARA pastoral em novos movimentos religiosos, com momentos quentes e lugares altos.

(5) DE Igreja estabelecida que oferecia aos jovens lugar próprio PARA Igreja indefinida, sem propostas para os jovens, e desafiada a ser construída na pluralidade de expressões.

(6) DE espiritualidade constante, sólida, lenta, estruturada PARA espiritualidade fulgurante, explosiva, breve, de curto prazo.

\section{Tendências na sociedade e na política}

(1) DE sociedade rural e industrial com horizontes mais ou menos estáveis PARA sociedade do conhecimento altamente móvel e flexível.

(2a) DE juventude crítica PARA a que remete para segundo plano a consciência crítica em face da realidade social e que desposa os valores da competência, do sucesso no mercado de trabalho. 
(2b) DA crítica ao consumismo e colonianismo dos EUA PARA a assimilação da cultura norte-americana e de seu estilo de vida.

(3a) DE juventude segregada da política passando por momento solidariedade consciente e forte politização PARA compromisso em casos emergenciais e festivos.

(3b) DE vida engajada politicamente e de despreocupação com a aparência exterior PARA o cultivo do corpo e da beleza externa.

(3c) DE juventude vinculada a ideais PARA juventude pragmática com ausência de práxis e de história.

\section{Conclusão}

Libanio encerra a obra "Para onde vai a juventude" relembrando ao leitor/a que embora tenha traçado um quadro amplo e geral, este permanece necessariamente incompleto. Sugere o confronto com a realidade concreta dos jovens, "para ser verificado, ampliado, eventualmente matizado ou corrigido" (p.247).

Embora reconhecendo tamanha diversidade de opções e direcionamentos, Libanio está convencido que os jovens, como maioria, tendem a adquirir feição pós-moderna. Essa se caracteriza por alguns traços predominantes, apontados numa breve tipologia em oito pontos (p.248-249).

A dinâmica de assimilação e discussão do texto, ao final do livro, reflete a perspectiva dialética e a percepção heurítica de Libanio, que ele ensina aos seus leitores e interlocutores. Pede-se para escolher uma tendência. Seguem-se as questões: "(1) Enumere os elementos positivos e significativos da tendência escolhida. (2) Indique-lhe os principais aspectos negativos e prejudiciais para os jovens. (3) Como você vê nela seu próprio retrato? (4) Como você prevê o seu desenvolvimento? (5) Aponte alguma sugestão pastoral para manter o aspecto positivo, superar o negativo e avançar para algo novo" (p.251).

A realidade juvenil, como o mundo contemporâneo, experimenta rápidas mudanças. Algumas, superficiais ou passageiras. Outras, levam a cabo tendências já apontadas por Libanio. Há ainda aquelas tendências que se desenvolvem em grupos minoritários, sejam anacrônicos ou progressistas, como reação e forma de enfrentamento.

Compete aos teólogos/as e aos pastoralistas a tarefa de, juntamente com os/as jovens, compreender esta realidade cambiante, com a ajuda de várias ciências humanas. E, sobretudo, fazer uma leitura esperança e propositiva, de 
forma a sair do "lugar comum" e de certo pessimismo que suscita sentimento de impotência e imobilismo.

Libanio nos deixa um caminho aberto, que ele começou muito bem. Ensina-nos a pensar a realidade de forma articulada, dialética, crítica e construtiva. Oxalá sua obra sobre a juventude seja difundida, aprofundada e ampliada.

\section{Referências bibliográficas}

KONINGS, J. (org). Teologia e pastoral. Homenagem ao Pe. Libanio. São Paulo: Loyola, 2012.

LIBANIO, J.B. O mundo dos jovens. Reflexões teológico-pastorais sobre os movimentos de juventude da Igreja. São Paulo: Loyola, 1978.

LIBANIO, J.B. Jovens em tempos de pós-modernidade. São Paulo: Loyola, 2004.

LIBANIO, J.B. Para onde vai a juventude? Reflexões pastorais. São Paulo: Paulus, 2011.

LIBANIO, J.B. Formação da consciência crítica. Petrópolis: Vozes.

- Vol 1: Subsídios filosófico-culturais. 1978;

- Vol 2: Subsídios sócio-analíticos, 1979;

- Vol 3: Subsídios psicopedagógicos, 1979.

MURAD, A; BOMBONATTO, V. (orgs), Teologia para viver com sentido. Homenagem aos 80 anos do teólogo João Batista Libanio. São Paulo: Paulinas, 2012. (contém os artigos de diferentes autores).

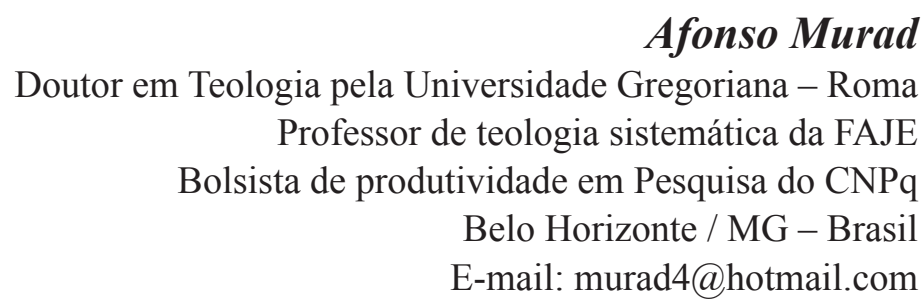

Recebido em: 17/10/14

Aprovado em: 29/10/14 